\title{
The Antioxidant Effects of Artemisia deserti Ethanolic Extract and Diazinon on Male Rat Kidney
}

\author{
Ali Noori, ${ }^{1, *}$ Leila Amjad, ${ }^{1}$ and Fereshteh Yazdani ${ }^{2}$ \\ ${ }^{1}$ Department of Biology, Falavarjan Branch, Islamic Azad University, Isfahan, IR Iran \\ ${ }^{2}$ Young Researchers and Elite Club, Falavarjan Branch, Islamic Azad University, Isfahan, Iran \\ "Corresponding author: Ali Noori, Department of Biology, Falavarjan Branch, Islamic Azad University, Isfahan, IR Iran. E-mail: ali.noori55@gmail.com
}

Received 2015 February 2; Accepted 2015 September 13.

\begin{abstract}
Background: Artemisia is a diverse genus of Asteraceae family that has pharmacological effects such as antiinflammatory, anticancer, antidiabetic and is used for treatment of diseases, including antioxidant effects against oxidative stress.

Objectives: This study investigated the antioxidant effects of Artemisia deserti Krasch extract and diazinon.

Materials and Methods: In this experimental study, Artemisia deserti was collected from Isfahan, Iran then 20 g of flower powder was extracted with $150 \mathrm{~mL} 80 \%$ ethanol and the $100,200 \mathrm{mg} / \mathrm{kg}$ concentrations of ethanolic extract were prepared. The 48 male rats were divided in to 6 groups include the 1 . Control, 2. diazinon treated group, 3. Diazinon + extract (100 mg/kg), 4. Diazinon + extract $(200 \mathrm{mg} / \mathrm{kg}), 5$ and 6 . extract treated groups $(100$ and $200 \mathrm{mg} / \mathrm{kg}$ ) respectively. The blood samples were collected and the rate of urea, uric acid, creatinine, serum total antioxidant and MDA (malondialdehyde) were assayed in serum. Also, the kidney tissue was isolated for histopathological examination. Finally, the statistical comparisons were done with one-way ANOVA test.

Results: The rate of creatinine and MDA were changed significantly in the group that had received the extract (200 mg/kg) alone. Moreover, results indicate tissue disorders in all groups compared to controls, including the degeneration of proximal and distal tubules, atrophied glomeruli and accumulation of inflammatory cells. These abnormalities were associated with oxidative stress in some groups.

Conclusions: Diazinon cause oxidative stress and kidney disorders, similar to the effect of artemisinin on kidney; therefore, simultaneous use of these compounds could enhance the toxic effects.

Keywords: Artemisia, Diazinon, Kidney
\end{abstract}

\section{Background}

Herbal medicine is used to prevent and treat of diseases over the world; moreover, they are known as the oldest form of human health care and they are usually without side effects. The world health organization estimates that $80 \%$ of the world populations use this herbal medicine $[1,2]$. The genus Artemisia is the largest and most widely of Asteraceae family which contains about 500 species [3]. Chemical study has shown that Artemisia species contain flavonoids, acetylenic compounds, coumarins and terpenoids, specifically sesquiterpene lactones. Artemisia deserti Krasch is a traditional medicinal herb of China, so that, it is cultivated on a commercial scale in Vietnam and China that this is probably due to presence of sesquiterpene lactones compounds [4]. Moreover, 16 components were detected in the oil of $A$. deserti aerial parts such as camphor (45.5\%), $\beta$-pinene (5.7\%), 1, 8-cineole (16.7\%), piperiton (8.6\%) and isoborneol (3.2\%) which these are main components in this plant. Also, the A. deserti flower and leaf oils were rich in oxygenated monoterpenes (68.2\% and 59.2\% respectively) while oxygenated monoterpenes (37.9\%) and sesquiterpenes (33.8\%) were the major in stem $[5,6]$.

The herbal medicine is as a source of phytochemicals that are known as biologically active antioxidants and these compounds inhibit free radicals [7]. Free radicals are highly reactive molecules that are produced by biochemical redox reactions occurring in natural process of cell metabolism, so that many diseases are caused by these molecules and antioxidant enzymes remove them from the body. Oxidative stress occurs when the free radicals are produced in large amounts or the antioxidant levels are low, as a result, the free radicals may cause lipid peroxidation and damage to cellular structures, nucleic acids, proteins and lipids. The level of lipid peroxidation is specified as malondialdehyde (MDA) $[8,9]$. Diazinon is an organophosphorous pesticide. Organophosphate compounds are useful for pesticides due to their ability to inhibit acetylcholinesterase, also, these compounds can damage different organs such as kidney in human and animals [10]. 


\section{Objectives}

Therefore, the aim of this study was comparison the effects of $A$. deserti extract and diazinon on rat kidney.

\section{Materials and Methods}

\subsection{Collection of Plants}

In this experimental study, the flowering tops of $A$. deserti were collected in west of Isfahan area (Golpaygan heights), Isfahan of province, Iran, in September 2012. The voucher specimen was deposited at the herbarium of the research-institute of Isfahan forests and rangelands. Preparation of extract: The flowering tops of $A$. deserti were air-dried under shade and ground in to coarse powder using electric blender, then, $20 \mathrm{~g}$ of flower powder were extracted with $150 \mathrm{~mL}$ 80\% ethanol by Soxhlet extraction for 8 hours. The residue was evaporated by using a rotary evaporator. The dried extracts were stored at $4^{\circ} \mathrm{C}$ until used. The extract was dissolved in saline at concentrations of 100 , $200 \mathrm{mg} / \mathrm{kg}$ body weight [11].

\subsection{Preparation of Diazinon}

Diazinon was procured from Sabzavar Pardis chemical company. Then, it was dissolved in distilled water at concentration of $100 \mathrm{mg} / \mathrm{kg}$ body weight.

\subsection{Animals}

Forty-eight Adult male Wistar rats (200 - 250 g) were obtained from Iran Pastor institute and divided into 6 groups of eight animals each. They were maintained in Falavarjan Azad university under controlled temperature, 12 hours light, 12 hours dark conditions for 1 week before the start of experiments for adaptation to laboratory conditions. The procedures in this study were carried out in accordance with the institution's scientific procedures for animals and were approved by the institutional animal care. The rats were randomly divided into the groups include the: 1 ) Control group that received normal saline, 2) Diazinon treated group (100 mg/kg), 3) Diazinon (100 mg/kg) + extract (100 $\mathrm{mg} / \mathrm{kg}$ ), 4) Diazinon (100 mg/kg) + extract (200 mg/kg), 5) and 6) Extract treated groups (100 and $200 \mathrm{mg} / \mathrm{kg}$ ) respectively. The rats were treated with diazinon (groups 2, 3, 4) once daily for 4 days (i.p.), 2 days after treatment they were treated with extract (groups 3, 4, 5, 6) once daily for 6 days (i.p.).

The rats were anesthetized by injection with ketamine ( $0.07 \mathrm{~mL} / 100 \mathrm{~g}$ body weight) and the blood samples were collected 2 days after the last injection of extract. The serum biochemical parameters including urea, uric acid and creatinine were assayed using autoanalyzer (902 Hitachi automatic analyzer, Roche, India) moreover, the rate of MDA and serum total antioxidant were assayed using TBA (Thiobarbituric Acid) and FRAP (Ferric Reducing Ability of Plasma) methods respectively $[12,13]$. Then, the rats were killed and kidney tissue was fixed in $10 \%$ formalin, dehydrated in ethanol, cleared in xylene and embedded in paraffin. Sections were prepared and then stained with Hematoxylin-Eosin (H and E) for photomicroscopic (Olympus, Japan) observation.

\subsection{Statistical Analysis}

All data were presented as Mean $\pm \mathrm{SD}$. The statistical comparisons were done with one-way ANOVA test (Duncan, $\mathrm{P}<0.05)$ by SPSS-18 software.

\section{Results}

According to the results, no significant changes were observed in the mean value of urea, uric acid and serum total antioxidant in all six groups; although the rate of these parameters changed between groups but these changes were not significantly. Whereas, the rate of creatinine was decreased significantly in group $6(200 \mathrm{mg} / \mathrm{kg}$ extract $)$ when compared with other groups $(\mathrm{P}<0.05)$ (Table 1$)$. Moreover, the rate of MDA was elevated significantly in the group 6 (200 mg/kg extract) $(\mathrm{P}<0.05)$ (Table 2$)$. Histological studies showed that the kidney tissue was normal in the control group. But, the treated rats with $A$. deserti extract and diazinon showed significantly histopathological alterations. These alterations were included the degeneration in the wall of proximal and distal tubules, atrophied glomeruli and swallowed endothelial cells. Also, some tubules were contained dense eosinophilic material and fluid or blood. Moreover, the inflammatory cells were observed in the kidney tissue (Figure 1). These changes were more in the groups treated with the extract (groups $3,4,5,6$ ) as compare with diazinon (group 2). Moreover, these changes were increased in the group 6 (concentration of $200 \mathrm{mg} / \mathrm{kg}$ extract) in compare with group 5 (concentration of $100 \mathrm{mg} / \mathrm{kg}$ extract).

\section{Discussion}

Results of this study showed that, the rate of creatinine was decreased significantly in group $6(200 \mathrm{mg} / \mathrm{kg}$ extract) as compared with other groups. In fact, the $A$. deserti extract $(200 \mathrm{mg} / \mathrm{kg}$ ) reduced the rate of creatinine in this group. Jayasimha Goud et al. also reported that Artemisia absinthium leaves methanol extract (100, 250 and $500 \mathrm{mg} / \mathrm{kg}$ ) produced significant hypoglycemic activity; 
Table 1. Comparison of Serum Biochemical Parameters Tested in 6 Groups

\begin{tabular}{|c|c|c|c|}
\hline Groups & Creatinine, mg/dL Mean \pm SD & Urea, $\mathrm{mg} / \mathrm{dL}$ Mean $\pm \mathrm{SD}$ & Uric Acid, $\mathrm{mg} / \mathrm{dL}$ Mean $\pm \mathrm{SD}$ \\
\hline Control & $0.575 \pm 0.07$ & $17.75 \pm 2.12$ & $0.775 \pm 0.265$ \\
\hline Diazinon (100 mg/kg) & $0.512 \pm 0.035$ & $19 \pm 1.77$ & $0.812 \pm 0.18$ \\
\hline $\begin{array}{l}\text { Diazinon }(100 \mathrm{mg} / \mathrm{kg})+\text { Artemisia deserti ethanolic extract (100 } \\
\mathrm{mg} / \mathrm{kg})\end{array}$ & $0.562 \pm 0.051$ & $16.62 \pm 2.06$ & $0.962 \pm 0.45$ \\
\hline $\begin{array}{l}\text { Diazinon }(100 \mathrm{mg} / \mathrm{kg})+\text { Artemisia deserti ethanolic extract } \\
(200 \mathrm{mg} / \mathrm{kg})\end{array}$ & $0.575 \pm 0.088$ & $18.00 \pm 2.00$ & $0.98 \pm 0.35$ \\
\hline Artemisia deserti ethanolic extract $(100 \mathrm{mg} / \mathrm{kg})$ & $0.537 \pm 0.0517$ & $19.37 \pm 3.11$ & $1.037 \pm 0.37$ \\
\hline Artemisia deserti ethanolic extract ( $200 \mathrm{mg} / \mathrm{kg})$ & $0.475 \pm 0.0462^{\mathrm{a}}$ & $20.12 \pm 2.9$ & $0.887 \pm 0.383$ \\
\hline
\end{tabular}

${ }^{a}$ Significant reduction $(\mathrm{P}=0.009)$ of creatinine in extract group $(200 \mathrm{mg} / \mathrm{kg}$ ) compared with all groups (one-way ANOVA, Duncan).

Table 2. Comparison of Malondialdehyde and Serum Total Antioxidant Tested in 6 Groups

\begin{tabular}{|c|c|c|}
\hline Groups & Malondialdehyde, nmol/mg Protein & Antioxidant, u/mg Protein \\
\hline & Mean \pm SD & Mean \pm SD \\
\hline Control & $0.87 \pm 0.703$ & $0.217 \pm 0.308$ \\
\hline Diazinon $(100 \mathrm{mg} / \mathrm{kg})$ & $0.96 \pm 0.462$ & $0.098 \pm 0.015$ \\
\hline Diazinon (100 mg/kg) + Artemisia deserti ethanolic extract (100 mg/kg) & $0.68 \pm 0.388$ & $0.113 \pm 0.040$ \\
\hline Diazinon $(100 \mathrm{mg} / \mathrm{kg})+$ Artemisia deserti ethanolic extract $(200 \mathrm{mg} / \mathrm{kg})$ & $0.60 \pm 0.375$ & $0.146 \pm 0.120$ \\
\hline Artemisia deserti ethanolic extract $(100 \mathrm{mg} / \mathrm{kg})$ & $0.97 \pm 1.60$ & $0.110 \pm 0.027$ \\
\hline Artemisia deserti ethanolic extract $(200 \mathrm{mg} / \mathrm{kg})$ & $1.97 \pm 0.511^{\mathrm{a}}$ & $0.106 \pm 0.022$ \\
\hline
\end{tabular}

${ }^{\mathrm{a}}$ Significant Increase $(\mathrm{P}=0.019)$ of Malondialdehyde in Extract Group $(200 \mathrm{mg} / \mathrm{kg}$ ) Compared with All Groups (one-way ANOVA, Duncan).

moreover, the extract of this plant reduced significantly the levels of urea and creatinine in diabetic rats. It can be probably due to hypoglycemic activity of this plant [14]. In other study, levels of creatinine, urea and uric acid were increased in diabetic rats; whereas Artemisia afra extract $(50,100$ and $200 \mathrm{mg} / \mathrm{kg})$ decreased these factors [15]. Moreover, Ene-ojo et al. reported that the chloroformic extract of Artemisia maciverae (50, 100 and $200 \mathrm{mg} / \mathrm{kg}$ ) increased the levels of urea and creatinine significantly compared to control group. The observed changes may be attributed to the toxic effects of plant extract that were dependent to dose and duration of treatment [11]. On the other hand, the extract of Artemisia monosperma was studied against lipid peroxidation induced by lead acetate. Lead administration increases significantly the amount of urea; but the extract of this plant reduced the level of urea to normal values; that may be due to high level of total antioxidant contents in this plant [16]. In present study, the rate of MDA elevated significantly in the group $6(200 \mathrm{mg} / \mathrm{kg})$ which indicate the extract of $A$. deserti caused oxidative stress in this group, while the rate of antioxidant enzymes were not changed. This result was not similar to the results of Temraz and ElTantawy that the antioxidant enzymes were increased in rats treated with the Artemisia vulgaris aqueous extract at $100 \mathrm{mg} / \mathrm{kg}$. These findings indicated that the extract of this plant is a potential source of natural antioxidants [17]. In the present study, the MDA did not change after treatment with diazinon. Whereas, in research of Amirkabirian et al. diazinon $(60 \mathrm{mg} / \mathrm{kg})$ increased significantly the rate of MDA in rats [18]. Jia et al. evaluated the antioxidant effect of Artemisisa selengensis water extract at concentrations of 3, $6,12 \mathrm{~g} / \mathrm{kg}$, that decreased significantly the MDA, especially $12 \mathrm{~g} / \mathrm{kg}$ [19]. In another study, the effect of the aqueous extract of Artemisia absinthium was investigated against CCl4 $(10 \mathrm{~mL} / \mathrm{kg})$. The extract at concentrations of 50, 100, 200 $\mathrm{mg} / \mathrm{kg}$ decreased the MDA and the antioxidant enzymes returned to normal. This indicated the protective effects of extract against acute liver injury may be attributed to its antioxidant and immunomodulatory activity [20].

The $A$. deserti extract and diazinon also, caused significant histopathological changes in the kidney tissue. Similar to our results, Sarhan and Al-Sahhaf investigated histopathological effects of diazinon on rabbits kidney so that diazinon $(20 \mathrm{mg} / \mathrm{kg})$ induced congestion of renal blood vessel and glomerulus, damage of renal tubules, glomeruli hypertrophy, swelling and proliferation in the 
Figure 1. Sections of the Kidney in the Control and Treated Groups
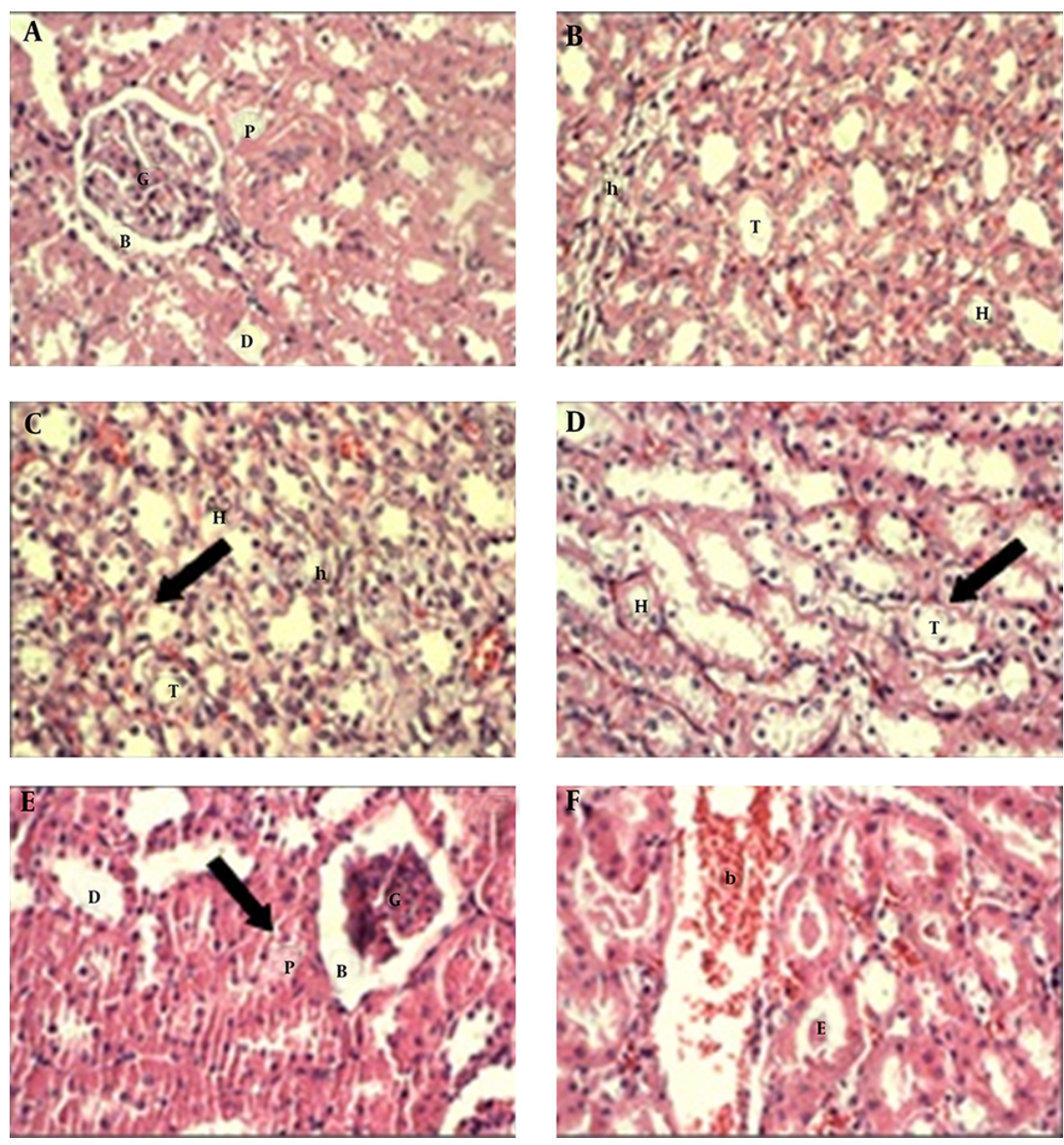

(A) The kidney cortex of control group shows that the glomerulus, proximal tubules, distal tubules and Bowman's capsule are normal. (B) The renal medulla of control group shows the thick and thin segments of ascending and descending loop of Henle, and collecting tubule are normal. (C) and (D) the renal medulla of treated groups with extract and diazinon show the degeneration in the lining epithelial cells of renal tubules and the nucleus of their cells release (arrow). (E) the kidney cortex of treated groups with extract and diazinon show the degeneration in the wall of renal tubules (arrow) and the atrophied glomeruli. (F) the kidney cortex of treated groups with extract and diazinon show several renal tubules contain dense eosinophilic material and eosinophilic fluid or blood.G, Glomerulus. B, Bowman's capsule. P, Proximal tubules. D, Distal tubules. H, thick segment of Henle. h, thin segment of Henle; T, collecting tubule. b, eosinophilic fluid or blood. E, Eosinophilic material $(400 \times)$.

lining endothelium of glomerulus [21]. Moreover, diazinon at concentrations of $80 \mathrm{mg} / \mathrm{kg}$ caused thickening the collecting tubules and degeneration of proximal tubules that these abnormalities may be due to oxidative stress [22]. In another study, diazinon $(16.25,32.5 \mathrm{mg} / \mathrm{kg}$ ) was tested in mice and only at $32.5 \mathrm{mg} / \mathrm{kg}$ caused kidney tissue damage that was dose-dependent [23]. Also, diazinon (50 mg/kg) consumption for 4 weeks showed congestion and inflammation in rat kidney tissue [24]. Salih reported increasing of uric acid and creatinin in treatment with diazinon ( $25 \mathrm{mg} / \mathrm{kg}$ ) for 20 days that is probably due to the formation of free radicals by diazinon [25]. Other researchers did not observe any significant alterations in rat kidney in $2 \%$ Artemisia abyssinica diet whereas degeneration and necrosis of the renal proximal epithelial cells were observed in $10 \%$ diet. These results showed the sensitivity of animals to plant materials was dependent to the active ingredient and concentration added to the diet [26]. According to the research, diazinon may cause oxidative stress. Moreover, the A. deserti flowering tops extract has toxic effects on kidney and this is probably due to the presence of Artemisinin (a toxic compound) that it is a sesquiterpene lactone that exist in Artemisia genus [27]. So that, these effects were increased with increasing of concentration of extract. On 
the other hand, A. deserti extract have probably the antioxidant effect but, it seems that, the lower concentrations with more treatment time with extract are close us to the desired results. Therefore, the extract of this plant at 100 and $200 \mathrm{mg} / \mathrm{kg}$ has not antioxidant activity. Ferreira et al. reported that artemisinin was metabolized by the liver CYP450 enzyme, but the pharmacological levels of artemisinin in the blood would decrease significantly after 5 - 7 days of treatment with the extract. This is due to induction CYP450 enzyme [28]. Therefore, more research needs to be done about the sampling time, number of injection and different concentrations of extract and diazinon.

\section{Acknowledgments}

The authors thank from the department of biology, Islamic Azad University, Falavarjan branch for their aid.

\section{Footnotes}

Authors' Contribution: All authors collaborated equally in perform the experiment and preparation of manuscript.

Funding/Support: Islamic Azad University, Isfahan, Iran.

\section{References}

1. Bodhisattwa M, Nagori BP, Rambir S, Kumar P, Upadhyay N. Recent trends in herbal drugs: A review. Int J Drug Res Tech. 2011;1(1):17-25.

2. Karakoca K, Ozusaglam MA, Cakmak YS, Erkul SK. Antioxidative, antimicrobial and cytotoxic properties of Isatis floribunda Boiss. ex Bornm. extracts. EXCLI J. 2013;12:150-67. [PubMed: 26417224].

3. Garcia S, McArthur ED, Pellicer J, Sanderson SC, Valles J, Garnatje T. A molecular phylogenetic approach to western North America endemic Artemisia and allies (Asteraceae): untangling the sagebrushes. Am J Bot. 2011;98(4):638-53. doi: 10.3732/ajb.1000386. [PubMed: 21613164].

4. Yazdani F, Noori A, Amjad L. Effect of Artemisia deserti flowering taps extract on liver in male rats. Int J Agric Crop Sci. 2013;5(13):1432.

5. Kazemi M, Shafizadeh S, Larijani K. Comparison of essential oils composition of stem, leaf and flower from artemisia deserti kracsh.J Appl Chem Res. 2011;18:29-34.

6. Noori A, Amjad L, Yazdani F. The effects of Artemisia deserti ethanolic extract on pathology and function of rat kidney. Avicenna J Phytomed. 2014;4(6):371-6. [PubMed: 25386400].

7. Molan AL, Faraj AM, Mahdy AS. Antioxidant activity and phenolic content of some medicinal plants traditionally used in Northern Iraq. Phytopharmaco. 2012;2:224-33.

8. Moujerloo M. Variations of lipid peroxidation and superoxide dismutase activity due to haemodialysis in gorgan. J Clin Diagn Res. 2010;4(4):2763-7.

9. Ugusman A, Zakaria Z, Chua K, Nordin NMM, Mahdy ZA. Flavanoids of Piper sarmentosum and its cytoprotective effects against oxidative stress. EXCLIJ. 2012;11:705-14.

10. Razavi M, Hosseinzadeh H, Abnous K, Motamedshariaty VS, Imenshahidi M. Crocin restores hypotensive effect of subchronic administration of diazinon in rats. Iran J Basic Med Sci. 2013;16(1):64-72. [PubMed: 25386400].
11. Ene-ojo A, Ene-ojo AS, Chinedu EA, Yakasai FM. Toxic Effects of Sub-Chronic Administration of Chloroform Extract of Artemisia maciverae Linn on the Kidney of Swiss Albino Rats. Int J Biochem Res Rev. 2013;3(2):119-28. doi: 10.9734/ijbcrr/2013/2062.

12. Esterbauer H, Cheeseman KH. Determination of aldehydic lipid peroxidation products: malonaldehyde and 4-hydroxynonenal. Methods Enzymol. 1990;186:407-21. [PubMed: 2233308].

13. Benzie IF, Strain JJ. Ferric reducing/antioxidant power assay: direct measure of total antioxidant activity of biological fluids and modified version for simultaneous measurement of total antioxidant power and ascorbic acid concentration. Methods Enzymol. 1999;299:15-27. [PubMed: 9916193].

14. Jayasimha GB, Danamma B, Nizamuddin SB, Dayananda KS, Chikka SBK. Hypo glycemic activity of a methanol extract of Artemisia absinthium leaves in experimental rats. Int I Adv Pharm Res. 2011;2(7):307-12.

15. Sunmonu TO, Afolayan AJ. Evaluation of Antidiabetic Activity and Associated Toxicity of Artemisia afra Aqueous Extract in Wistar Rats. Evid Based Complement Alternat Med. 2013;2013:929074. doi: 10.1155/2013/929074. [PubMed: 23861717].

16. Al-Soqeer A. Antioxidant Activity and Biological Evaluation of Hot-water Extract of Artemisia monosperma and Capparis spinosa Against Lead Contamination. Res J Bot. 2011;6(1):11-20. doi: 10.3923/rjb.2011.11.20.

17. Temraz A, El-Tantawy WH. Characterization of antioxidant activity of extract from Artemisia vulgaris. PakJ Pharm Sci. 2008;21(4):321-6. [PubMed: 18930849].

18. Amirkabirian N, Teimouri F, Esmaily H, Mohammadirad A, Aliahmadi A, Abdollahi M. Protection by pentoxifylline of diazinoninduced toxic stress in rat liver and muscle. Toxicol Mech Methods. 2007;17(4):215-21. doi: 10.1080/15376510600943783. [PubMed: 20020971].

19. Jia $X, Z$ Zhao $C$, Chen $Y$. The in vitro and in vivo antioxidant activities of various extracts from Artemisisa selengensis Turcz. Recent Advances in Clinical Medicine. UK: University of Cambridge; 2010.

20. Amat N, Upur H, Blazekovic B. In vivo hepatoprotective activity of the aqueous extract of Artemisia absinthium L. against chemically and immunologically induced liver injuries in mice. J Ethnopharmacol. 2010;131(2):478-84. doi:10.1016/j.jep.2010.07.023. [PubMed: 20637853].

21. Sarhan OMM, Al-Sahhaf ZY. Histological and biochemical effects of diazinon on liver and kidney of rabbits. Life Sci.J. 2011;8(4):1183-9.

22. Hassan SA, El-Shawaf IM, El-Ghazaly A, El-Azab SM. Ozone Administration Ameliorates Different Chemically Induced Hepato-Renal Chronic Toxicity in Rats: a Histopathological Study. Forensic Med Clin Toxicol. 2007;15(2):57-72.

23. El-Shenawy NS, Al-Eisa RA, El-Salmy F, Salah O. Prophylactic effect of vitamin $\mathrm{E}$ against hepatotoxicity, nephrotoxicity, haematological indices and histopathology induced by diazinon insecticide in mice. Curr Zool. 2009;55(3):219-26.

24. Shokrzade M, Abbasi A, Shadborestan A, Omidi M. Pathology examination of liver and kidney in diazinon exposed rat and role of Lcarnitine [in Persian]. JMUMS. 2013;22(2):140-4.

25. Salih EMA. Toxic effect of dimethoate and diazinon on the biochemical and hematological parameters in male rabbits. Jordan J Biol Sci. 2010;3(2):77-82.

26. Adam SE, Al-Qarawi AA, Elhag EA. Effects of various levels of dietary Artemisia abyssinica leaves on rats. Lab Anim. 2000;34(3):307-12. [PubMed: 11037126].

27. Chaturvedi D. Sesquiterpene lactones: structural diversity and their biological activities, In-Opportunity, Challanges and Scope of Natural Products in Medicinal Chemistry. Research Signpost. 2011;1(2):313-4.

28. Ferreira JF, Luthria DL, Sasaki T, Heyerick A. Flavonoids from Artemisia annua L. as antioxidants and their potential synergism with artemisinin against malaria and cancer.Molecules. 2010;15(5):3135-70. doi: 10.3390/molecules15053135. [PubMed: 20657468]. 